\title{
UTILIZATION OF PULVERISED COAL MONITORING SYSTEM FOR CLEANER ELECTRICITY GENERATION
}

\author{
M. F. Muhamad Said ${ }^{1}$ and A. Aroussi ${ }^{2}$ \\ ${ }^{1}$ Automotive Development Center, Transportation Research Alliance, Faculty of \\ Mechanical Engineering, Universiti Teknologi Malaysia \\ 81310 UTM Johor Bahru, Malaysia \\ Phone : +607-5534658; Fax : +607-5535811 \\ Email: mfarid@fkm.utm.my \\ ${ }^{2}$ Department of Mechanical \& Industrial Engineering, College of Engineering, Qatar \\ University, Qatar
}

\begin{abstract}
This paper describes a utilization of the coal monitoring system, which is a clamp-on particle sizer (CPS) device for monitoring particle size at the outlet of a classifier model. The device is examined in terms of its capability to characterize moving particles in the classifier outlet pipe. The architecture and working principle of the device are explained. The device employs a high intensity continuous laser as a light source and a digital camera to capture the particle images. The image analysis technique has been implemented in extracting valuable information about the particles from the images. Image processing algorithms were applied in the development of the software and are described in this paper. In order to evaluate the repeatability of the CPS device technique, the measurement was repeated three times. The deviation result confirmed that the technique has a good repeatability in sizing the moving particles. Validation was performed by comparing the CPS with shadow device. Mean sizes obtained by the CPS device had differences of between 3.5 to $5 \%$ compared with the shadow device. The capacity of the CPS device was successfully examined by by measuring the small size and speed of the moving particles.
\end{abstract}

Keywords: Particle characterization; particle size; coal monitoring; image processing.

\section{INTRODUCTION}

In the last half-century, global energy consumption has increased rapidly and is expected to grow over the next 25 years. From 1980 to 2006, primary energy demand in the world has shown an average annual increase of 1.9\% (IEA, 2008). Fossil fuels accounted for about $80.9 \%$ of total primary energy demand in 2006 . This includes consumption of oil, coal and natural gas at $34.3 \%, 26 \%$ and $20.5 \%$, respectively. Electrical power, transportation, heating and industry are the major sectors using primary energy sources. Statistics from the International Energy Agency (IEA) World Energy Outlook 2008 shows that the global demand for electricity increased by nearly a quarter between 2000 and 2006 (IEA, 2008). This was due to electricity becoming the preferred form of energy for various consumer products and industry applications. Pulverized coal power stations dominate the electric power industry by providing the thermal energy which produces about $41 \%$ of the world's electric supply. It is designed and constructed to convert energy from fuel, coal, into electric power. It produces 
electricity by burning pulverized coal to generate the thermal energy for a boiler. This coal-fired boiler provides steam to drive large turbines. Coal is the world's second most important fuel after oil, accounting for $26 \%$ of global energy demand. It remains the main fuel for power generation. In 2005, global electricity generation from coal-fired power stations reached over $40 \%$ of the total (IEA, 2007). This is illustrated in Figure 1 where coal is the main contributor as the source of electricity production.

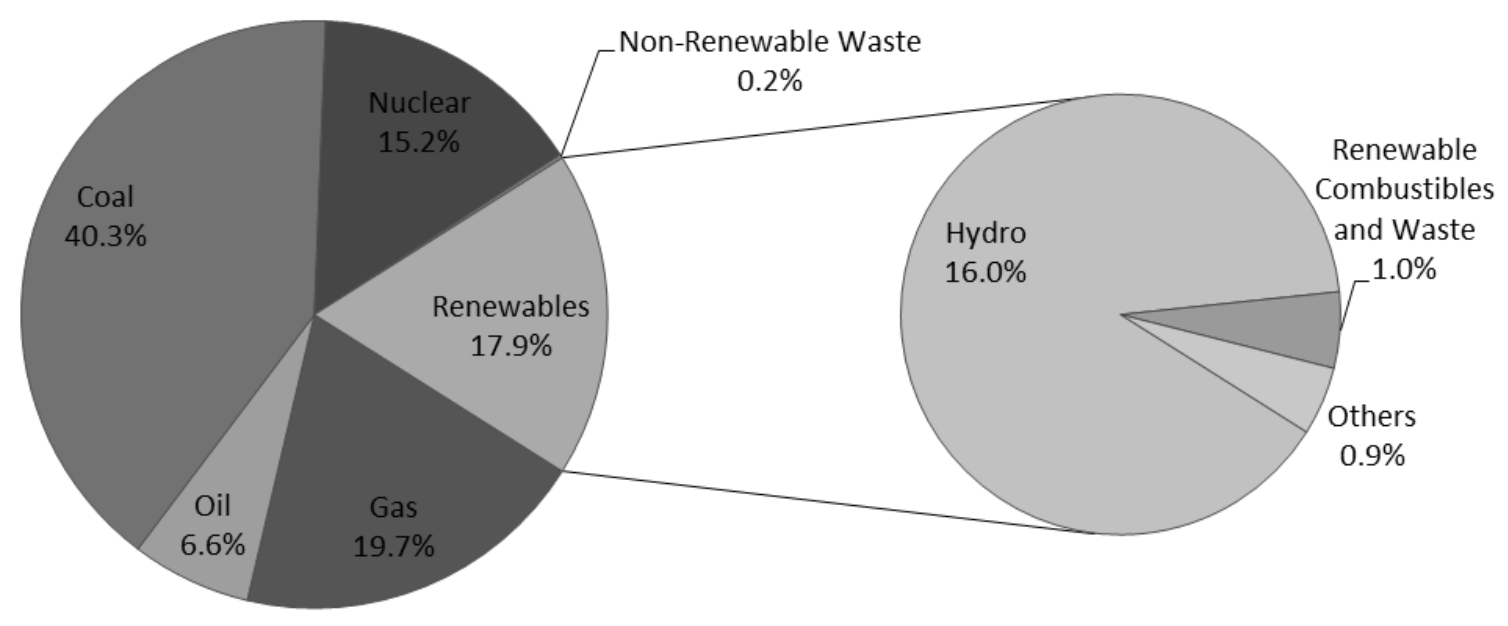

Figure 1. Fuel shares in world electricity production in 2005 (IEA, 2007).

Globally, coal remained the dominant source of electricity generation in 2035, although its share declined to $41 \%$ by 2008, and is predicted to decline to $32 \%$ by 2035 . On the other hand, power generation based on fossil-fuels emitted about $41 \%$ of the world's $\mathrm{CO}_{2}$ emissions. Emissions from coal alone reached $73.5 \%$ of total power emission, while gas and oil produced $\mathrm{CO}_{2}$ at $19.5 \%$ and $7 \%$, respectively. Pulverized coal units cause significant environmental concerns (Belošević, Tomanović, Beljanski, Tucaković, \& Živanović, 2013; Czarnowska \& Frangopoulos, 2012; Shen, Liu, Zhang, \& Jiang, 2013). Emissions of sulfur and nitrogen oxides contribute to acid rain and ozone formation and are dangerous to human and ecosystem health. Other emissions include particulate matter, heavy metals such as mercury and arsenic, and carbon dioxide. Because coal is largely composed of carbon, with relatively little hydrogen, its combustion leads to a higher level of carbon dioxide emissions per unit of energy released than do petroleum-based fuels or natural gas (Goswami \& Kreith, 2007; Muda $\&$ Boosroh, 2013). In protecting our environment, cleaner electricity generation is very important for coal-fired power stations, and so emissions have to be controlled and well managed. One method involves improving the first stage of coal as supplied to the burner which is in a pulverizer. This paper describes the use of a fuel management system, the clamp-on particle sizer device, in monitoring the size of particles from a classifier outlet model.

\section{PULVERISED COAL MONITORING SYSTEM}

\section{Description of Pulverizer}

The pulverizer is equipment that consists of a grinder and a classifier. It is usually used in coal-fired power stations to crush the coal and to ensure that the optimum size of coal 
particles for burning is below 75 microns. This finer size of coal is very important in the combustion process so that higher efficiency and lower emissions from power generation can be achieved. In coal-fired power stations, pulverized coals from the grinder are delivered to a device that sorts wide particle size distribution by size. These are called classifiers. They allow a certain cut size to proceed to the burner, while rejecting the particles that are above this pre-determined cut size. The larger particles are then re-directed back to the grinder, where they are crushed further. For experimental purposes, a laboratory scale model is about a third the size of a typical classifier, and designed to mimic an industrial air classifier (Afolabi, Aroussi, Mat Isa, \& Al-Atabi, 2009). Its design is based on the vertical spindle mill static classifier with four outlets (Figure 2).

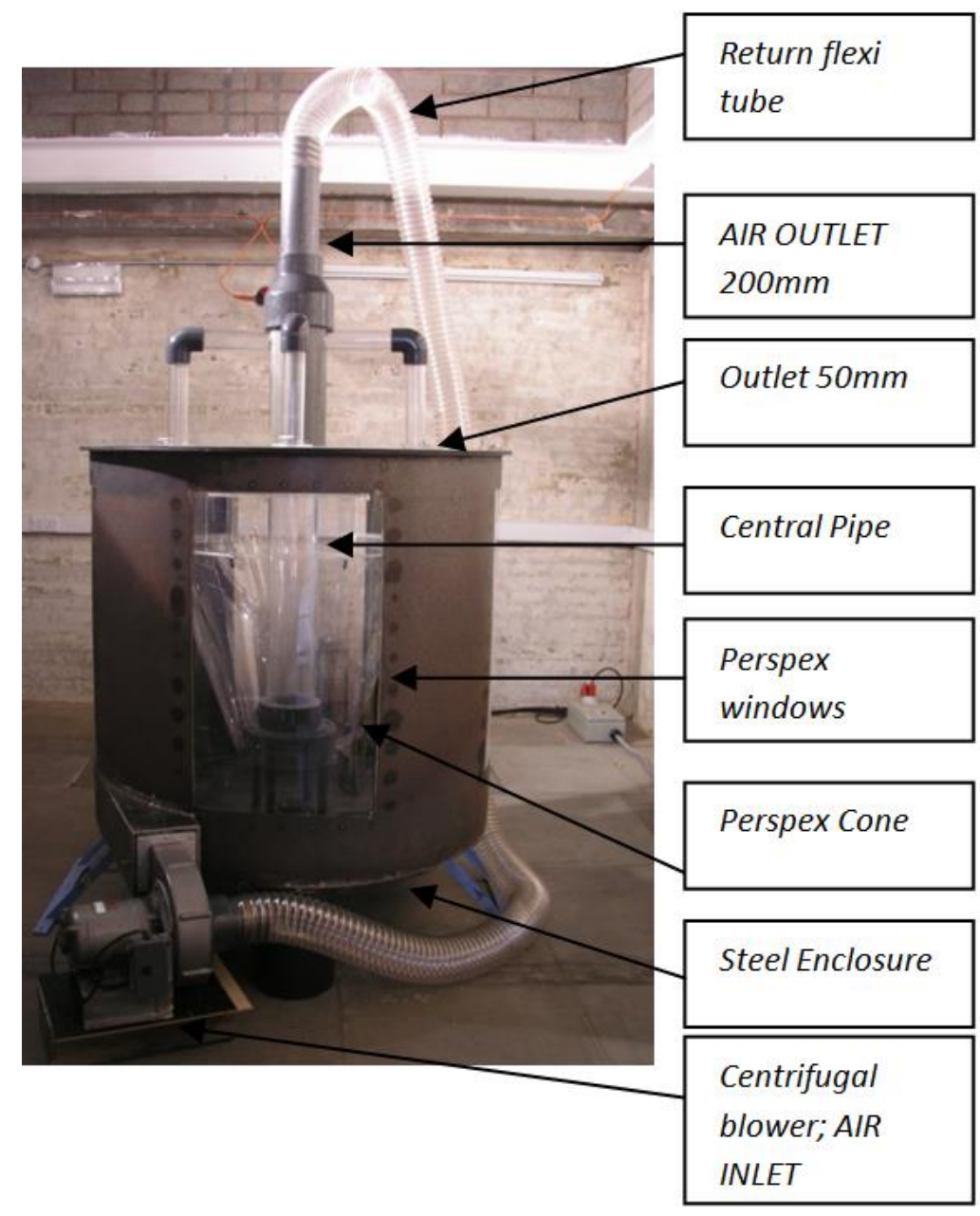

Figure 2. The laboratory scale classifier model (Afolabi et al., 2009).

\section{Clamp-on Particle Sizer}

This is device developed in-house and used specifically to monitor online particle size at the outlet of the classifier. It is installed in one of the classifier outlets to monitor the coal or particle size distribution. It is based on optical and digital image analysis techniques and was developed for the automated determination of the properties of particles, such as their size. The principles of optical based particle characterization have been discussed by many researchers (Tinke et al., 2008; Tropea, 2011). In this 
study, the device required 8-bit digital images of the solid-gas flow under investigation. Analysis of the images was performed through an automated processing algorithm. In this study, the CPS is applied to obtain the size distribution of particles at the outlet of the classifier pipe.

\section{EXPERIMENTAL SETUP}

The CPS device is based on the extraction of information from digital images. In order to acquire these images, several pieces of equipment were used. The following sections describe the function of each component and also explain the CPS system setup.

\section{Components of the CPS Device}

Four major components were used in the development of CPS, which include a laser, a digital camera, a compact vision system (CVS) and a monitor. All these components were integrated, to make the whole system work (Figure 3(a)). A software program was developed using LabView codes in order to perform automated image processing and analysis tasks.

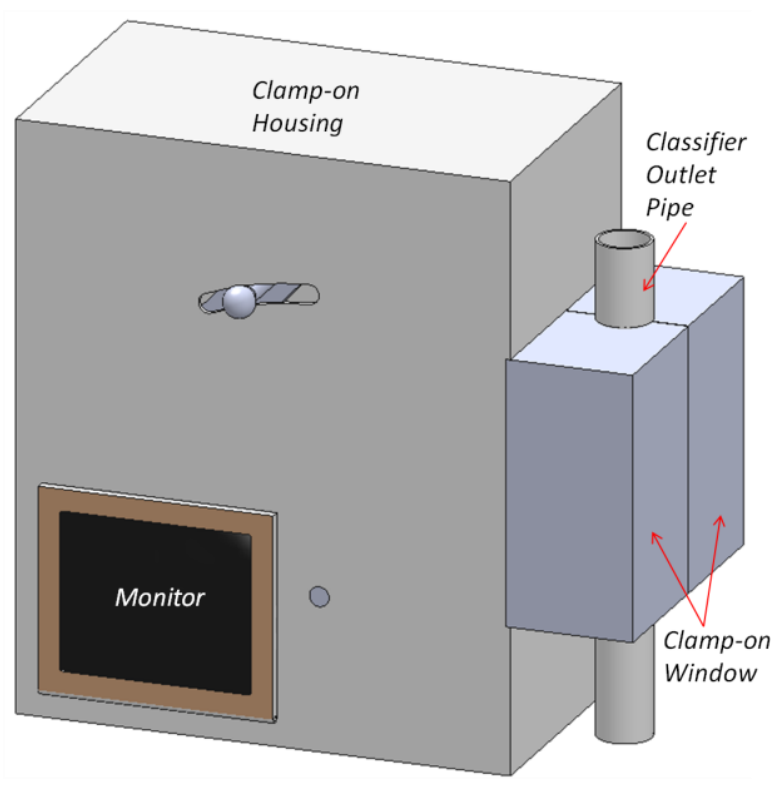

(a)

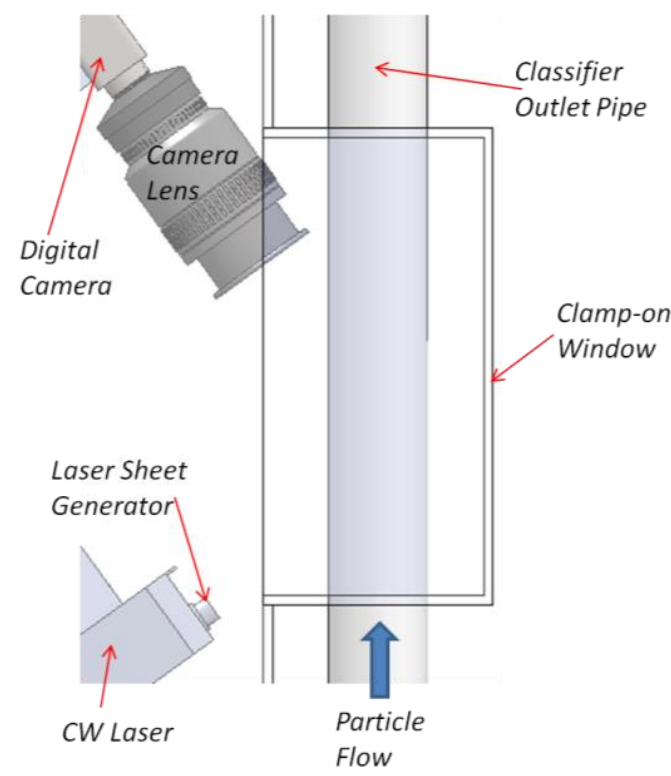

(b)

Figure 3. (a) Clamp-on particle sizer and (b) Components inside the device.

Figure 3(b) shows the setup of the components inside the clamp-on housing. A continuous wave (Nakatsu \& Hughes, 2008) laser was used as a light source for the digital camera. A proper amount of light is necessary so that good quality particle images can be achieved. The maximum output of the laser is 2 watts and it produced a $1.8 \mathrm{~mm}$ continuous beam size, with a $532 \mathrm{~nm}$ wavelength. The laser beam is converted to a laser sheet using a cylindrical rod.

A digital camera is used to capture illuminated particles in the classifier outlet pipe. It is equipped with IEEE1394-b connectors to allow a fast image transfer speed. This monochrome camera has a resolution of up to $1280 \times 960$ pixels. The position of the camera and the laser is set to be perpendicular, similar to that of the particle image 
velocimetry setup (PIV). A compact vision system (CVS) is used as a platform to control the image acquisition of the camera. The developed software is installed in the CVS in order to run a stand-alone application that performs an online measurement of particle size. The CVS is equipped with an embedded processor to process and analyze images acquired by the camera. A monitor is used to display online results. These results are obtained from the developed software where the software automatically processes and analyzes the acquired images and plots them into graphs. The purpose of the CPS device is to characterize small micron-sized particles, thus, it is important to have a higher magnification of image. A $60 \mathrm{~mm}$ micro-lens equipped with a spacer is therefore used in this study. As a result, the field of view (FOV) of the image, with a resolution of $1280 \times 960$ pixels, is $5.24 \mathrm{~mm} \times 3.93 \mathrm{~mm}$. The optical configuration of this current setup has produced an image magnification factor of 0.92 and has a $150 \mathrm{~mm}$ working distance.

\section{Measurement of Particle Size}

In this experiment, fillite (grade 160) particles were used to mimic the pulverized coal in the classifier. The CPS was installed on one of the outlets of the classifier. A centrifugal blower was switched on to run the classifier (Figure 2). The speed of the blower was controlled to ensure a certain cut size proceeded to the outlet, and the particles above this pre-determined cut size were dropped to base of classifier. The CPS device was based on the direct illumination technique. A continuous laser sheet was produced to illuminate the particles in the outlet pipe. A sequence of images was acquired by the camera at high shutter speed. This high speed is required to freeze the movement of the particles. Once an image was acquired by the camera, it was then directly transferred to the memory of the CVS via an IEEE-1394b FireWire cable for processing. The image was processed and analyzed using the developed software in order to obtain the droplet size distribution and mean size. Online results were then seen things on a monitor.

\section{Digital Image Processing and Analysis}

The image analysis technique was applied to extract valuable information from the images (Hess \& L'Esperance, 2009). Once the raw image was received by the software, it was processed to enhance its appearance and then analyzed to extract the desired information, such as number of pixels occupied by a single particle. The developed software was produced using a LabView code. This similar program has been used to characterize spray particles as discussed by previous researchers (Aroussi, Lad, Muhamad Said, Adebayo, \& Al-Atabi, 2010; Muhamad Said \& Aroussi, 2010). The flowchart of the algorithms is outlined in Figure 4. After image acquisition, the first processing stage was image enhancement, a process to improve an image so that it looks subjectively better (Petrou \& Bosdogianni, 1999). In this study, the approach was to enhance the image by changing the brightness, contrast and gamma values. The filter function was also applied to compute backgrounds in order to correct the light drifts.

The second stage of image processing was image segmentation. This extracted the outlines of different regions in the image so as to divide the image into regions which are made up of pixels. In this case, thresholding was used to separate the particles from the background. In order to obtain the area of a single particle, the number of pixels that represented a single dark object was calculated. 


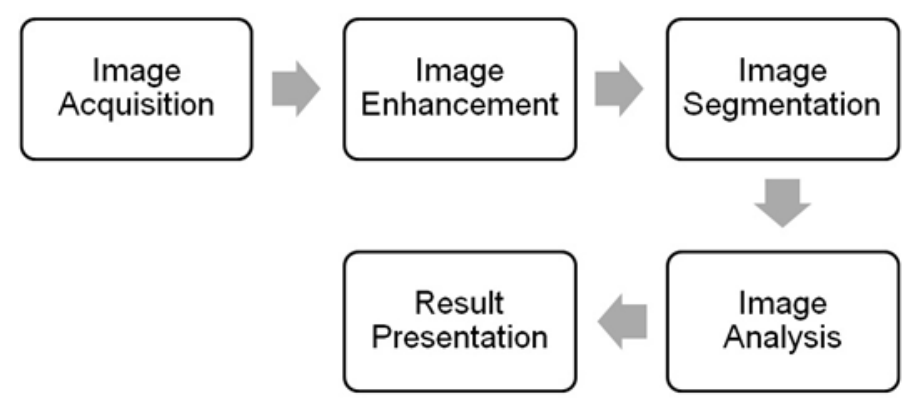

Figure 4. Algorithms of the developed software

This algorithm also determined the number of particles per image. An algorithm of result presentation was created to calculate the particle diameter based on the area of the particles, and to display a real-time plot of their size distribution. In this case, the calculation of particle size was based on equivalent diameter as shown in Equation (1).

$$
D_{p}=2 \sqrt{\frac{A_{p}}{\pi}}
$$

where $D_{p}$ was the equivalent diameter of the particle and $A_{p}$ was the area of the particle (Kashdan, Shrimpton, \& Whybrew, 2003). This developed software identified every particle in the image and maintained a list of data that contained information regarding each of the particles.

\section{RESULTS AND DISCUSSION}

In this study, the fillite particles size that flow inside a classifier outlet pipe were measured using a CPS device. A direct illumination technique was applied to obtain particles images. In this method, the particles were directly illuminated with a light sheet, and a camera acquired the scattered image of the particles. A fast shutter speed in the camera was used to freeze the particles in motion so that the camera could capture clear particle images. The images were then processed and analyzed using the developed software to obtain the drop size distribution and mean size. Particle size measurement through a shadow sizing device was also performed to validate the CPS results.

\section{Image Calibration}

In principle, the image analysis system used images to determine particle size, therefore, calibration against known size or dimension was critical to the validity of the results. A calibration image was used to assess the absolute accuracy of the system, where a known dimension image was used to transform a pixel coordinate to a real-world coordinate through scaling in the $\mathrm{x}$ and $\mathrm{y}$ (horizontal and vertical) directions. In this experiment, a static image were used for the calibration. The camera was positioned over a known dimension of graph paper which was placed on a flat surface. The image was translated from pixels to micron units. Figure 5 depicts the calibration plot of the 
image. It shows that $1 \mathrm{~mm}$ of distance was equal to 240 pixels, so it could be concluded that one pixel of image was equal to $0.0041 \mathrm{~mm}$ or $4.1 \mu \mathrm{m}$.

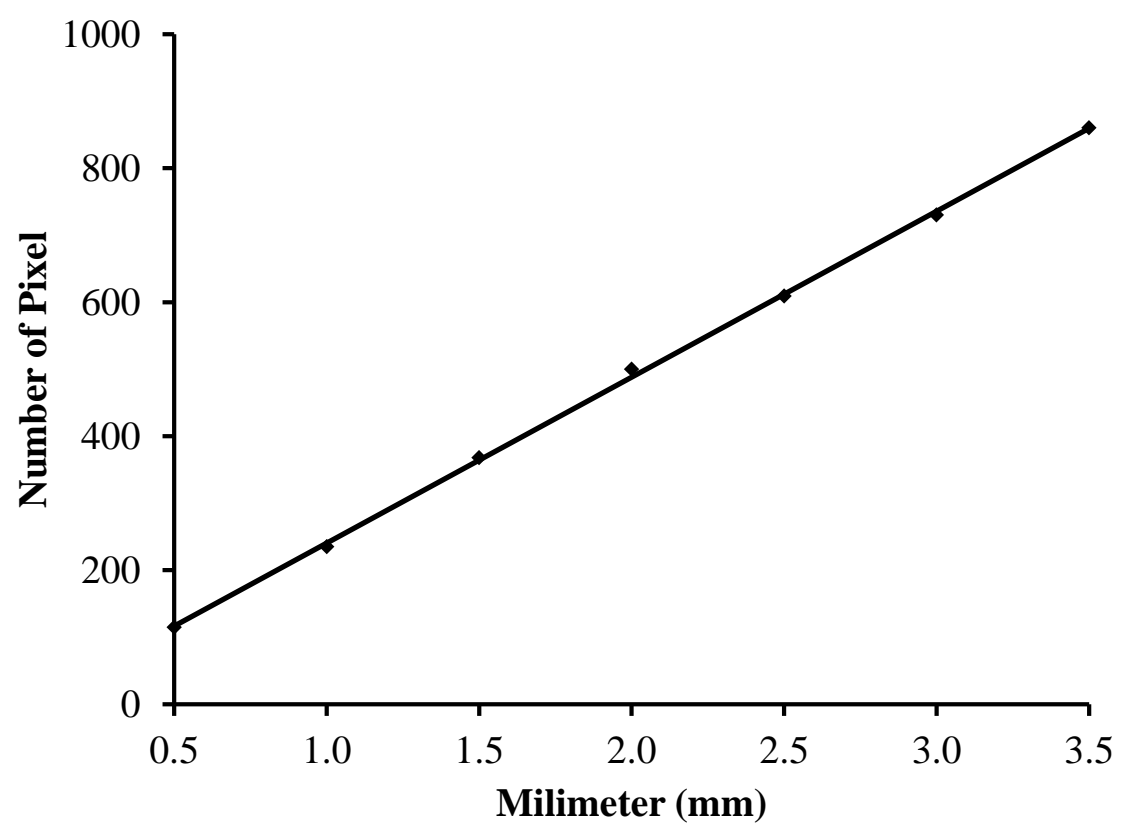

Figure 5. Image calibration plot.

\section{Particle Size Analysis}

Figure 6(a) shows an acquired image of fillite particles at the classifier outlet pipe. It shows that the particles did not overlap due to a lower concentration of the particles. There were also some blurred particle images depicted, which was due to the camera being out of focus. In order to determine an accurate particle size distribution, only infocus images of particles were selected during the image segmentation process. Figure 6(b) therefore shows that the number of particles on a processed image is less than on the captured image. The acquired raw image was enhanced and segmented to produce the processed image as described in previous section.

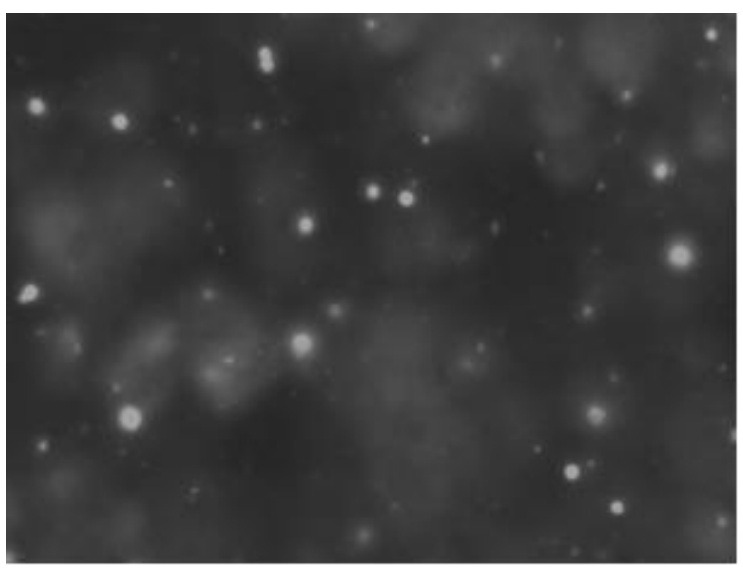

(a)

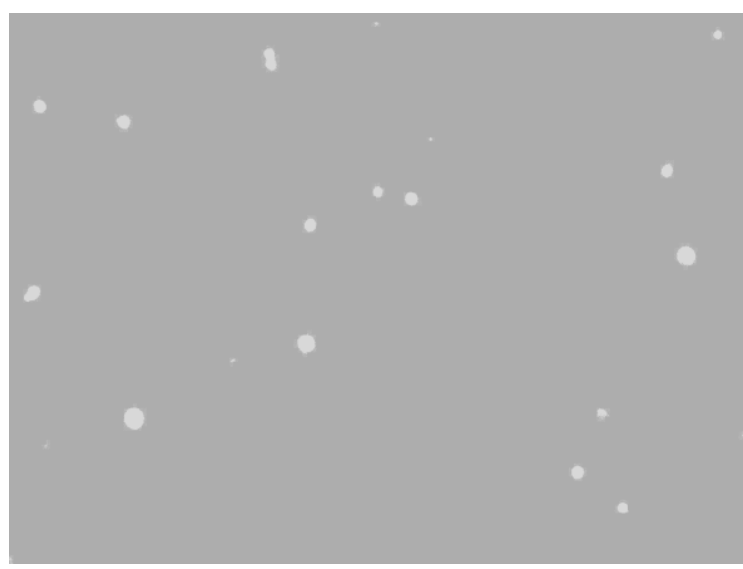

(b)

Figure 6. (a) Captured image, and (b) Processed image by CPS device. 
Figure 7 shows the actual raw image recorded by shadow device. The shadow device captured shadow images of particles and used a pulsed laser light to freeze the particle movement. Figure 8(a) illustrates a comparison of the volume size distribution between CPS and the shadow sizing device. Both devices are similar in terms of the shape of the plot. The measured particle size distributions for both show that the size ranges were from 20 to $220 \mu \mathrm{m}$. A total of approximately 4000 particles were detected for each device in producing the distribution. Figure 8(b) shows the cumulative volume distribution that was calculated based on the volume distribution (Allen, 1997). It clearly shows that the CPS result agreed closely with the shadow. Both methods detected $100 \%$ of the particles were below $220 \mu \mathrm{m}$.

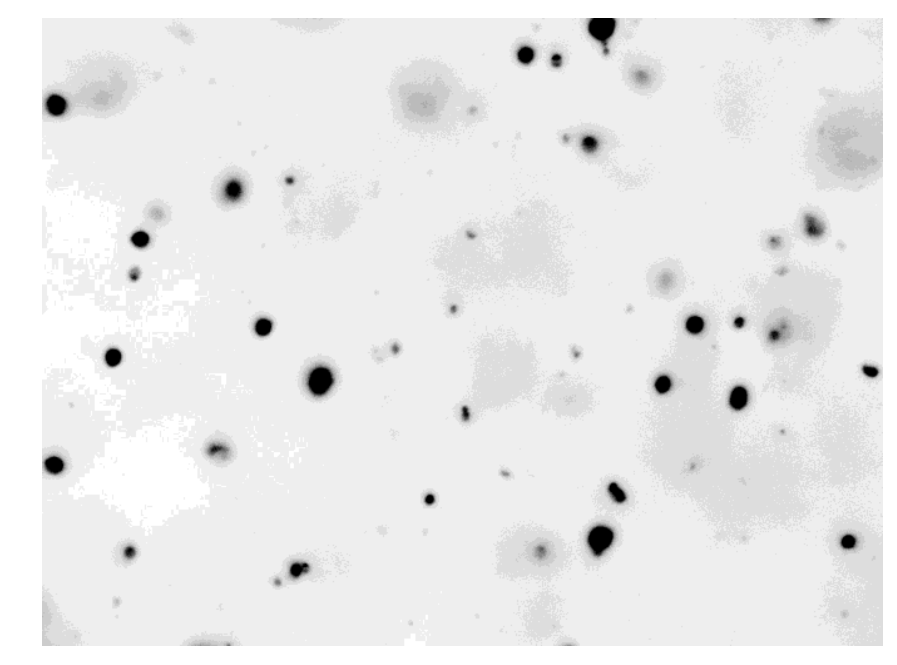

Figure 7. Actual raw image acquired by shadow device

Figure 9(a) shows that the CPS measured approximately 73, 114 and $152 \mu \mathrm{m}$ of the particles that were below $10 \%, 50 \%$ and $90 \%$, respectively. The shadow device detected lower sizes, with percentage differences at $12 \%, 6 \%$ and $2 \%$. The CPS also measured a 5\% higher Arithmetic Mean and 3.5\% increase in Sauter Mean Diameter (SMD) compared to the shadow device (Figure 9(b)). The higher values detected by the CPS device are probably due to the high intensity of light scattered by the particles. As mentioned earlier, the device is based on a direct illumination technique where the particles are in direct contact with the light sheet, so the sizes obtained by CPS may appear bigger than those obtained by shadow.In this study, fillite particle sizing by CPS device was repeated three times to investigate the repeatability of the technique. For each test, at least 100 images were acquired and analyzed. On average, 35 particles were detected on each image.

Figure 10 shows the deviation data in three different tests. Deviation is the difference between average particle sizes in each test with the mean particle size. The result is that all the tests produced less difference compared to each other. The deviation for all tests were recorded as below 10\%. This means that the CPS has a good repeatability in sizing the particles. 


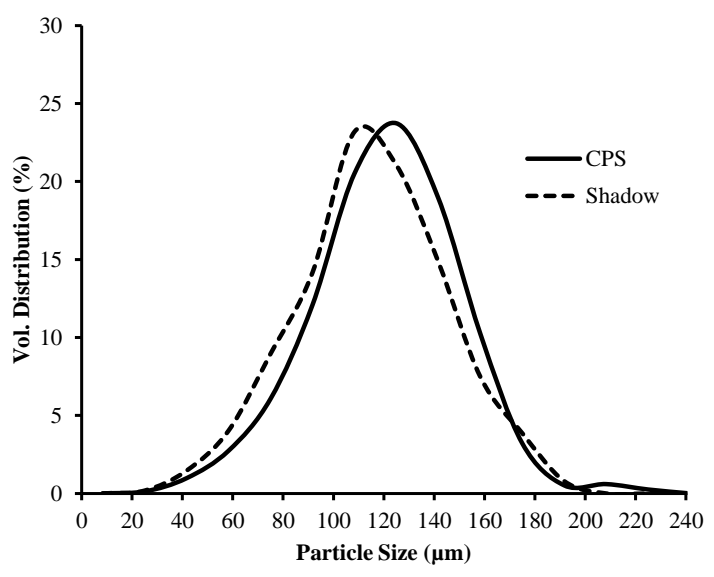

(a)

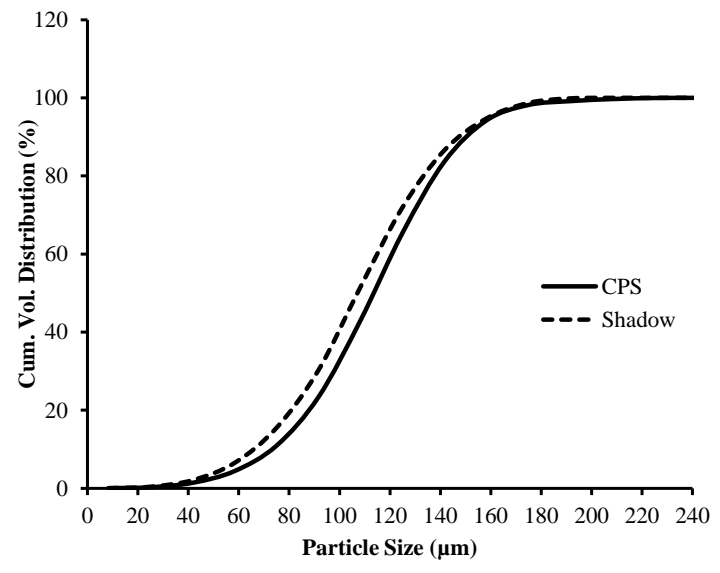

(b)

Figure 8. (a) Volume size distribution and (b) Cumulative volume size distribution

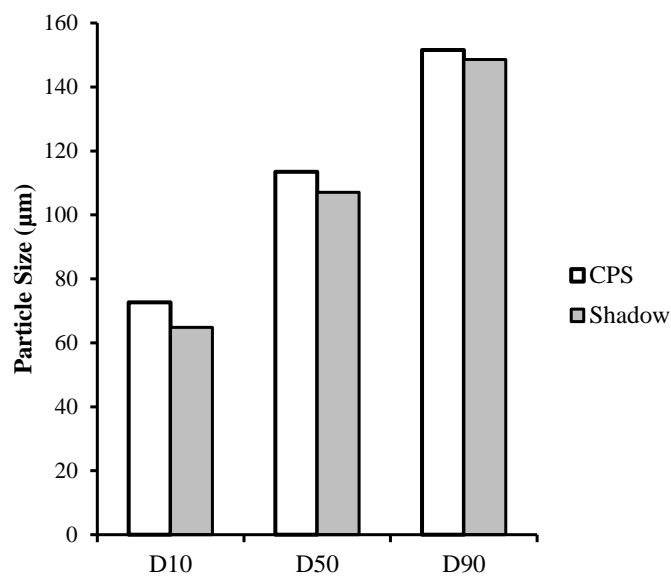

(a)

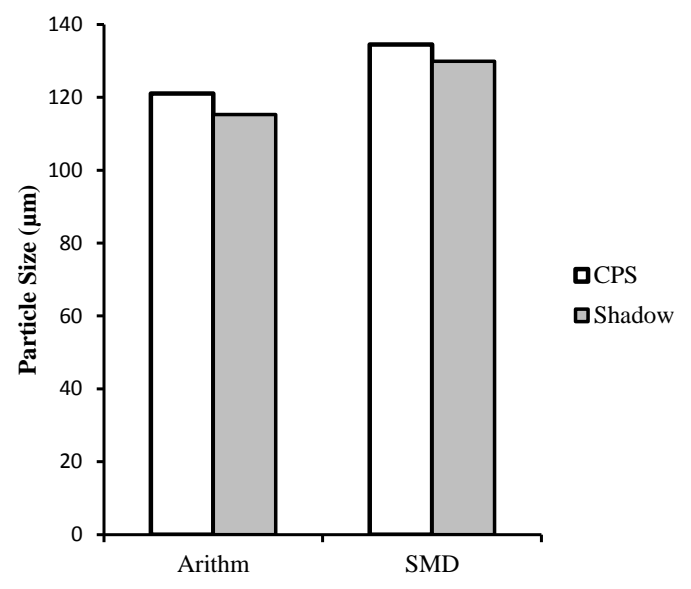

(b)

Figure 9. (a) Particle Size at 10\%, 50\% and 90\% of Cumulative Distribution, and (b) Mean Diameters 


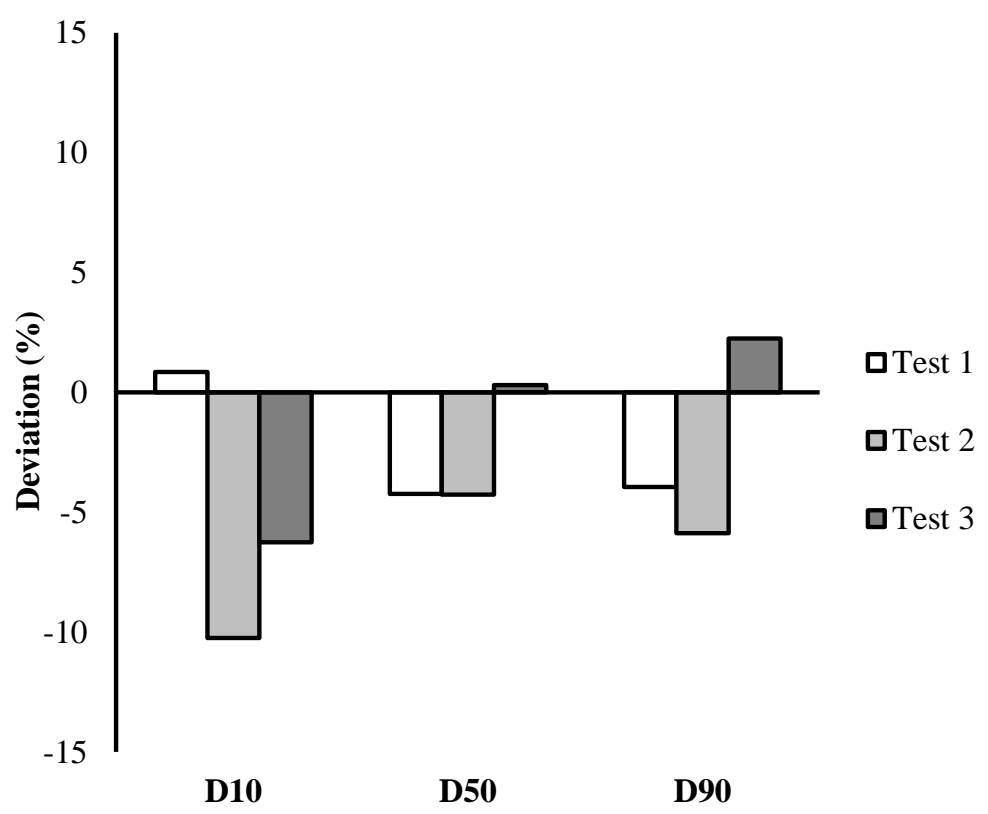

Figure 10. Deviation results for three different tests.

\section{CONCLUSIONS}

This paper has presented the utilization, operational principles and evaluation of a pulverized coal monitoring system, the CPS device. The device was tested for its measurement of solid fillite particle size distribution and mean size at the classifier outlet pipe model. Image enhancement and image segmentation were applied to eliminate the particles which were not in focus. This was important to obtain accurate particle size. The CPS device has good repeatability in sizing moving particles. This was confirmed through the deviation results of this study. Mean sizes obtained by the CPS device showed increments between 3.5 to $5 \%$ compared with the shadow device. This was believed to be due to the high intensity of light scattered by the particles, where the particles were in direct contact with the light sheet. The ability of the CPS device was examined by successfully measuring small sized and fast moving particles.

\section{ACKNOWLEDGMENTS}

The author acknowledges financial support from the Universiti Teknologi Malaysia and Ministry of Higher Education Malaysia (MOHE) under the research university grant Q.J130000.2624.07J26. The author is also grateful for the assistance of Dr. Abdelwahab Aroussi (Qatar University).

\section{REFERENCES}

Afolabi, L., Aroussi, A., Mat Isa, N., \& Al-Atabi, M. (2009). The prevailing fluid motion in a model coal classifier. Paper presented at the 4th Algerian Congress of Process Engineering 2009, Algiers, Algeria.

Allen, T. (1997). Particle size measurement (Vol. 1). London: Chapman \& Hall. 
Aroussi, A., Lad, N., Muhamad Said, M. F., Adebayo, D., \& Al-Atabi, M. (2010). The interaction of a cold atomised spray with a circular cylinder. Journal of Engineering Science and Technology, 5(3), 361-372.

Belošević, S., Tomanović, I., Beljanski, V., Tucaković, D., \& Živanović, T. (2013). Numerical prediction of processes for clean and efficient combustion of pulverized coal in power plants. Applied Thermal Engineering, In press Online Available in 18 November 2013.

Czarnowska, L., \& Frangopoulos, C. A. (2012). Dispersion of pollutants, environmental externalities due to a pulverized coal power plant and their effect on the cost of electricity. Energy, 41(1), 212-219.

Goswami, D., \& Kreith, F. (2007). Energy conversion. Boca Raton: CRC Press.

Hess, C. F., \& L'Esperance, D. (2009). Droplet imaging velocimeter and sizer: A twodimensional technique to measure droplet size. Experiments in Fluids, 47(1), 171-182.

IEA. (2007). Renewable information 2007. France: International Energy Agency.

IEA. (2008). World energy outlook 2008. France: International Energy Agency.

Kashdan, J. T., Shrimpton, J. S., \& Whybrew, A. (2003). Two-phase flow characterization by automated digital image analysis. Part 1: Fundamental principles and calibration of the technique. Particle \& Particle Systems Characterization, 20, 387-397.

Muda, N., \& Boosroh, M. H. (2013). Gasification of coal-petcoke blends in a pilot scale gasification plant. International Journal of Automotive and Mechanical Engineering, 8, 1457-1466.

Muhamad Said, M. F., \& Aroussi, A. (2010). On-line measurement of droplet size using digital imaging analysis techniques. Paper presented at the The $14^{\text {th }}$ International Symposium on Flow Visualization (ISFV14), Daegu, South Korea.

Nakatsu, M. N., \& Hughes, C. C. (2008). An optimized three-dimensional in vitro model for the analysis of angiogenesis. Methods in Enzymology, 443, 65-82.

Petrou, M., \& Bosdogianni, P. (1999). Image processing: The fundamentals. Singapore: John Wiley.

Shen, J., Liu, J., Zhang, H., \& Jiang, X. (2013). Nox emission characteristics of superfine pulverized anthracite coal in air-staged combustion. Energy Conversion and Management, 74(0), 454-461.

Tinke, A., Carnicer, A., Govoreanu, R., Scheltjens, G., Lauwerysen, L., Mertens, N.et al.Brewster, M. (2008). Particle shape and orientation in laser diffraction and static image analysis size distribution analysis of micrometer sized rectangular particles. Powder Technology, 186(2), 154-167.

Tropea, C. (2011). Optical particle characterization in flows. Annual Review of Fluid Mechanics, 43, 399-426. 